\title{
Editorial
}

\section{Low level exposure to asbestos: is there a cancer risk?}

In the early days of asbestos use when its harmful potential was not understood hygiene standards at the workplace were extremely low. Airborne dust concentrations were uncontrolled and fibre levels in excess of 100 per $\mathrm{ml}$ were not unusual. This type of exposure led to the discovery that inhalation of asbestos produced pulmonary fibrosis,' bronchial carcinoma, ${ }^{2}$ and mesothelioma. ${ }^{3}$ Efforts to reduce concentrations of asbestos fibre began in the 1930s and, since the 1950s, increasingly stringent limits have been imposed by law. Some countries have banned many uses of asbestos, although it remains almost essential for some special packing and friction products. Various fibre substitutes have been introduced in advanced countries, especially for plastic or cement products, though these are generally less durable and more costly. The latter point is a serious matter in third world countries where asbestos cement products are well-nigh essential for water and drainage pipes and for building construction. In addition, it now seems possible that some manmade mineral fibres could carry similar risks to health. ${ }^{4}$

The use of asbestos today in the developed world may only be undertaken under strict control, in most countries at levels of $1 \mathrm{fibre} / \mathrm{ml}$ or less. Exposure levels in buildings and in the general environment of our cities, resulting from the use of asbestos products, are far lower still. The question of whether such low occupational and environmental exposures are free from risk has become a major practical, social, and legal issue.

As it is apparent that controlling dust has largely eliminated the risk of pulmonary asbestosis, the main concern is now over cancer and whether or not there is a safe threshold below which asbestos does not cause tumour production. Evidence on this matter is afforded by both experimental studies in laboratory animals and epidemiological studies in human populations exposed to asbestos. Both approaches have their limitations. Animals may be exposed to measured doses of asbestos but their short life span makes direct extrapolation of the results to man difficult. Epidemiological studies, on the other hand, suffer from great uncertainty about the precise nature and intensity of exposure, especially in the distant past. Whereas the impossibility of proving a complete negative is accepted, both the epidemiological and experimental findings provide a basis for rational decisions.

Experimental studies have shown that the pathological effects of asbestos depend not only on the mass of dust deposited in the lung tissues but on fibre length and durability. Wagner et al reported on rats exposed to the main types of asbestos in which a constant mass of dust was administered for periods of one day to two years. ${ }^{5}$ The degree of diffuse pulmonary fibrosis varied proportionately with duration of exposure. The experience of rats exposed for one day only was similar to that of unexposed control animals. The production of pulmonary tumours was less clearly related to duration but in general more tumours occurred in animals exposed for long periods. Some animals exposed for a single day developed pulmonary tumours but, again, similar numbers were found in control animals. Information is needed on the effect of a range of doses administered over a long period but such studies have not been undertaken. The production of mesotheliomas by intratracheal or intraperitoneal injection of asbestos provides a less expensive method of examining the carcinogenic effects of widely varied doses. Davis reported studies in which reference samples of crocidolite, amosite, and chrysotile had been injected into the peritoneal cavities of rats at doses from $25 \mathrm{mg}$ down to $0.01 \mathrm{mg} .{ }^{6}$ A clear dose response was found with all three types of asbestos fibre, but whereas crocidolite did not produce tumours at the lowest dose level, chrysotile and amosite did. With each fibre type, the relation was linear when plotted on a log scale; however, with all three, both the time to first tumour and the mean induction period increased progressively with reducing dose. Tumours produced by the lowest doses in general occurred during the last few months of the rat's life, suggesting that lower doses still had insufficient time to produce any tumours.

It also appears that not all fibres are equally harmful and evidence is accumulating that very short fibres may be innocuous. Both Stanton and Wrench and Pott and Friedrichs reported that dust samples which produced the most mesotheliomas in rats were those that contained the highest number of long and thin fibres. ${ }^{78}$ This work has been progressively refined, and it is now evident from injection studies that the most dangerous fibres are those with a length $>8 \mu \mathrm{m}$ and a 
diameter of $<0.25 \mu \mathrm{m} .{ }^{9}$ When any fibres longer than 8 $\mu \mathrm{m}$ are considered, the lowest injected doses $(0.01 \mathrm{mg})$ which produced any tumours contained about 410000 fibres of chrysotile and 110000 fibres of amosite; a dose containing 60000 fibres of crocidolite produced none. At all dose levels chrysotile was the most carcinogenic dust followed by amosite, with crocidolite the least so.

Long term inhalation studies have recently been conducted using short fibre preparations of amosite and chrysotile. ${ }^{111}$ In these experiments the effect of short fibre dust was compared with a normal dust cloud of the same batch of asbestos containing many long fibres. The amosite preparation was extremely short with almost no fibres greater than $5 \mu \mathrm{m}$ in length; the short fibre chrysotile was less satisfactory in that some long fibres remained. Whereas the long fibres of both chrysotile and amosite produced large amounts of pulmonary fibrosis and a considerable number of pulmonary tumours, the short fibre amosite preparation produced neither fibrosis nor tumours. Short fibre chrysotile produced a small amount of fibrosis and some tumours, roughly in proportion to the number of long fibres present.

There remains the question of whether, to cause disease, asbestos fibres need be retained in the lung for long periods; a low retained dose might well produce little disease regardless of the number of fibres inhaled. In this respect chrysotile and the amphibole varieties differ appreciably. After varying inhalation periods at high dose levels, rats have been shown to retain up to ten times more amphibole than chrysotile. ${ }^{\text {s1 }}$ The recent studies of Davis et al have extended these findings to include fibre length. ${ }^{910}$ Fewer long than short fibres were present at the end of dusting for both chrysotile and amosite; the elimination of short fibres was faster than that of long but, regardless of size, chrysotile was cleared from lung tissue much faster than amosite. Amphibole fibres are extremely durable even in aggressive chemical environments whereas chrysotile undergoes decompositon readily, even in water. Davis et al reported that in rats, 18 months after inhalation of chrysotile at high doses for one year, no fibres remained in pulmonary macrophages or in direct contact with any of the other pulmonary cells. ${ }^{12}$ Only a few fibres were detected and these in old acellular fibrous tissue or in thickened basement membranes, chemical backwaters where fibre dissolution is retarded. The rapid removal of chrysotile and the durability of amphilbole fibres have also been noted in several studies of human lung tissues. ${ }^{13-15}$

Whereas epidemiological studies in man can attempt to measure risk directly their capacity to do so becomes increasingly unreliable as the level of exposure falls. Partly, this is due to deficiencies in exposure data but mainly it is because no reference population is ever more than roughly comparable with the exposed study group. Thus in not one of the ten or so eligible cohort studies of lung cancer mortality in asbestos workers does the fitted line for exposure response pass through the origin unless forced to do so. ${ }^{16}$ Even the remarkably good approximation to linearity observed in these data sets is possibly determined more by duration than intensity - these two components of exposure not having yet been separately assessed. Valid though the results of well designed observational surveys are, for these reasons alone any estimate of risk carries a wide margin of possible error. In chrysotile mine and mill workers, for example, no statistically significant increase in lung cancer mortality would have been detected in nearly 2000 men with at least 20 years employment at an average airborne fibre concentration of about 20 fibres/cc, though the linear exposure response hypothesis would imply that there was one. ${ }^{17}$ Even in the far more hazardous environment of asbestos textile factories the same would probably be true up to levels of about 2 fibres $/ \mathrm{ccc}^{18}$ Such levels are as high or higher than current occupational limits and orders of magnitude above those causing concern in public buildings. It also appears that in amosite asbestos factory workers the lower the estimated dose, the longer it took for related mortality to become evident and the smaller its magnitude. ${ }^{19}$

The epidemiological data on exposure response are much more tenuous for mesothelioma than for lung cancer. Such quantitive information as there is points to a direct relation between the risk of this disease and some combination of duration and intensity of exposure, but strongly modified by fibre type. There is now considerable evidence that pure chrysotile per se seldom causes mesothelioma in man and that most cases are due to amphibole fibres-crocidolite and amosite in particular-but increasing attention is now being directed at fibrous tremolite. Tremolite asbestos has little or no commercial value but commonly contaminates many mineral deposits, some of which, such as chrysotile, talc, and vermiculite, are widely used industrially, and others not. The potential importance of the tremolite factor, noted by Pooley and Rowlands et al, was directly shown in vermiculite miners and millers whose only exposure to mineral fibres was from contaminating tremolite. ${ }^{132021}$ The lung cancer and mesothelioma experience of this cohort was, dose for dose, many times worse than that of Quebec chrysotile miners and millers. The contribution of fibrous tremolite to mortality from these causes had also been suspected in New York State talc miners many years earlier. ${ }^{22}$ Although the proportion of tremolite in asbestos dust in the Quebec mines and mills is less than $1 \%$, most fibres found at necropsy in the lungs of both mine workers and chrysotile textile 
factory workers are of this type, not chrysotile. ${ }^{23}$ It thus seems probable that even the relatively low risk of mesothelioma in individuals reputedly exposed only to chrysotile may largely result from tremolite contamination.

Further insight into the magnitude of the risk of cancer from low level exposure may be obtained from national trends in mesothelioma incidence and mortality. During the past 20 to 30 years the pattern has been remarkably similar in the United States, Canada, Britain, and probably Scandinavia.$^{24}$ The data suggest that, until the $1950 \mathrm{~s}$, the annual mortality from mesothelioma was similar in men and women, at about 1-2 per million. Since then the trends have separated; mortality in men has risen steeply in parallel with using asbestos some 30 to 40 years earlier whereas in women there has been no significant increase. The female trend is particularly important since it is known that cases have occurred in women who have worked with asbestos or lived in the household of asbestos workers. It would be expected, moreover, that during the years in question increased awareness of what was once considered a rare tumour might lead to improved ascertainment. If, despite this, there has been no apparent increase in female mortality in a combined population of some 300 million subjects observed for at least 15 years the risk attributable to non-occupational exposure must be extremely small.

What conclusions may be drawn from a synthesis of these experimental and epidemiological findings? We cannot say, and it may be impossible to prove or disprove that at very low levels of exposure to asbestos the risk of cancer is zero. None the less, further statistical analyses are needed to test the linearity of risk in relation to intensity of exposure. So far as lung cancer is concerned, clearly any increase in risk at exposure below today's control limits, even in men who smoke more than they now do, would not be detected. The same could be said for mesothelioma in relation to commercial chrysotile but with less confidence for the commercial amphiboles, crocidolite, and amosite. If the tremolite contamination could be removed from chrysotile the safety margin would be wider. Plausible explanations for these assertions have been shown in the laboratory. Chrysotile is poorly retained and rapidly cleared from the respiratory tract; short fibres, which predominate in low level pollution, have little or no carcinogenic potential; with decreasing dose tumour latency may be prolonged beyond the normal life span. General toxicological experience, and the probability of defence mechanisms, would also suggest the existence of an effective threshold, or at least a sigmoid form of exposure-response.

The adverse effects of asbestos have probably been more extensively studied than any other environ- mental hazard; and manmade mineral fibres may well require the same attention. It seems unlikely that much more scientific information on asbestos can be expected than is now available. Rational decisions will depend on questions of cost, benefit, and the appreciation of risk. It will be for society, not science, to decide what priority should be given to the reduction of unsubstantiated and undetectable risks, even from such dreaded effects as mesothelioma and lung cancer.

J M G DA VIS

Institute of Occupational Medicine, Edinburgh

\section{Department of Clinical Epidemiology, Brompton Hospital, London SW3 $6 \mathrm{HP}$.}

\section{References}

1 Cooke WE. Pulmonary asbestosis. Br Med J 1927;ii: 1024-5.

2 Lynch KM, Smith WA. Pulmonary asbestosis iii. Carcinoma of the lung in asbestos silicosis. Am J Cancer 1935;24:56-64.

3 Wagner JC, Sleggs CA, Marchand P. Diffuse pleural mesothelioma and asbestos exposure in the North Western Cape Province. Br J Ind Med 1960;17:260-71.

4 Conference report. International symposium on man-made mineral fibres in the working environment, Copenhagen, 28-29 October 1986. Ann Occup Hyg 1987;31:99-102.

5 Wagner JC, Berry G, Skidmore JW, Timbrell V. The effects of the inhalation of asbestos in rats. Br J Cancer 1974;29:252-69.

6 Davis JMG. A review of recent experiments on the mechanisms of asbestos pathogenicity. In: Proceedings of Vth international colloquium on dust measuring technique and strategy, Johannesburg. Asbestos International Association 1985:25-35.

7 Stanton MF, Wrench C. Mechanisms of mesothelioma induction with asbestos and fibrous glass. Br J Cancer 1972;48:797-821.

8 Pott F, Friedrichs KH. Tumours in rats after intraperitoneal injection of asbestos dusts. Naturwissenschaften 1972;59: 318-32.

9 Davis JMG, Addison J, Bolton RE, Donaldson K, Jones AD, Smith T. The pathogenecity of long versus short fibre samples of amosite asbestos administered to rats by inhalation and intraperitoneal injection. Br J Exp Pathol 1986;67:415-30.

10 Davis JMG, Jones AD, Smith T. Comparisons of the pathogenicity of long and short fibre samples of chrysotile asbestos in rats. Edinburgh: Institute of Occupational Medicine, 1987. (Tech memo TM 87/08.)

11 Middleton AP, Beckett ST, Davies JMG. A study of the shortterm retention and clearance of inhaled asbestos using UICC standard reference samples. In: Walton WH, ed. Inhaled particles IV. Oxford: Pergamon Press, 1977:247-57.

12 Davis JMG, Bolton RE, Brown D, Tully HE. Experimental lesions in rats corresponding to advanced human asbestosis. Exp Mol Pathol 1986;44:207-21.

13 Pooley FD. An examination of the fibrous mineral content of asbestos in lung tissue from the Canadian chrysotile mining industry. Environ Research 1976:12:281-98.

14 Gylseth B, Mowe G, Wannag A. Fibre type and concentration in the lungs of workers in an asbestos cement factory. Br J Ind Med 1983;40:375-9.

15 Sebastien P, Begin R, Case BW, McDonald JC. Inhalation of chrysotile dust. In: Wagner JC, ed. Biological effects of chrysotile. Philadelphia: JB Lippicott Co, 1987:19-29.

16 McDonald JC, McDonald AD. Epidemiology of asbestos-related 
lung cancer. In: Antman K, Aisner J, eds. Asbestor-related malignancy. London: Grune and Stratton Inc, 1987:57-79.

17 McDonald JC, Liddell FDK, Gibbs GW, Eyssen GE, McDonald AD. Dust exposure and mortality in chrysotile mining, 1910-75. $\mathrm{Br} J$ Ind Med 1980;37:11-24.

18 McDonald AD, Fry JS, Woolley AJ, McDonald JC. Dust exposure and mortality in an American chrysotile textile plant. Br J Ind Med 1983;40:361-7.

19 Seidman H, Selikoff IJ, Gelb SK. Mortality experience of amosite asbestos factory workers: dose-response relationships five to 40 years after onset of short-term work exposure. Am J Ind Med 1986;10:479-514.

20 Rowlands N, Gibbs GW, McDonald AD. Asbestos fibres in the lungs of chrysotile miners and millers: a preliminary report. Ann Occup Hyg 1982;26:411-5.

21 McDonald JC, McDonald AD, Armstrong B, Sebastien P. Cohort study of mortality of vermiculite miners exposed to tremolite. $\mathrm{Br}$ J Ind Med 1986;43:436-44.

22 Kleinfeld M, Messite J, Kooyman O, Zaki MH. Mortality among talc miners and millers in New York State. Arch Environ Health 1967;14:663-7.

23 Sébastien P, McDonald JC, McDonald AD, Case B, Harley R. Respiratory cancer in chrysotile textile and mining industries; exposure inferences from lung analysis. $\mathrm{Br} J$ Ind Med (in press).

$24 \mathrm{McDonald}$ JC. Health implications of environmental exposure to asbestos. Environ Health Perspect 1985;62:319-28.

\section{Vancouver style}

All manuscripts submitted to the $B r J$ Ind Med should conform to the uniform requirements for manuscripts submitted to biomedical journals (known as the Vancouver style)

The $\mathrm{Br} J$ Ind Med, together with many other international biomedical journals, has agreed to accept articles prepared in accordance with the Vancouver style. The style (described in full in Br Med J, 24 February 1979, p 532) is intended to standardise requirements for authors.

References should be numbered consecutively in the order in which they are first mentioned in the text by Arabic numerals above the line on each occasion the reference is cited (Manson' confirmed other reports ${ }^{2-5} \ldots$.). In future references to papers submitted to the $\mathrm{Br} J$ Ind Med should include: the names of all authors if there are six or less or, if there are more, the first three followed by et al; the title of journal articles or book chapters; the titles of journals abbreviated according to the style of Index Medicus; and the first and final page numbers of the article or chapter.

Examples of common forms of references are:

1 International Steering Committee of Medical Editors. Uniform requirements for manuscripts submitted to biomedical journals. Br Med J 1979;1:532-5.

2 Soter NA, Wasserman SI, Austen KF. Cold urticaria: release into the circulation of histamine and eosino-phil chemotactic factor of anaphylaxis during cold challenge. $N$ Engl $J$ Med 1976;294:687-90.

3 Weinstein L, Swartz MN. Pathogenic properties of invading micro-organisms. In: Sodeman WA Jr, Sodeman WA, eds. Pathologic physiology: mechanisms of disease. Philadelphia: W B Saunders, 1974:457-72. 